\title{
Estratégias de mediação cultural: Inovação e experimentação no Serviço Educativo da Casa da Música
}

Innovation and Experimentation in Cultural Mediation Strategies: The Case of the Casa da Música Education Service

Innovation et expérimentation dans les stratégies de médiation culturelle : le cas du Service Éducatif de la Casa da Música

Pedro Quintela

\section{OpenEdition}

\section{Journals}

Edição electrónica

URL: http://journals.openedition.org/rccs/1531

DOI: $10.4000 /$ rccs. 1531

ISSN: 2182-7435

\section{Editora}

Centro de Estudos Sociais da Universidade de Coimbra

Edição impressa

Data de publição: 1 setembro 2011

Paginação: 63-83

ISSN: 0254-1106

Refêrencia eletrónica

Pedro Quintela, «Estratégias de mediação cultural: Inovação e experimentação no Serviço Educativo da Casa da Música », Revista Crítica de Ciências Sociais [Online], 94 | 2011, posto online no dia 01 outubro 2012, consultado o 10 dezembro 2020. URL : http://journals.openedition.org/rccs/1531 ; DOI : https://doi.org/10.4000/rccs. 1531

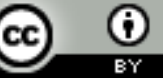




\section{PEDRO QUINTELA}

\section{Estratégias de mediação cultural: Inovação e experimentação no Serviço Educativo da Casa da Música*}

O tema da mediação cultural readquiriu nas três últimas décadas muita relevância nos discursos políticos e programáticos que apelam à formação e atração de públicos para as artes e a cultura. Este apelo, muito associado ainda aos princípios da "democratização cultural", traduz igualmente as preocupações de sustentabilidade sentidas por agentes e instituições culturais, num contexto em que o poder público tende a desvincular-se do financiamento à cultura. Em Portugal, estas preocupações vêm suscitando o desenvolvimento dos chamados "serviços educativos" e de novas estratégias de mediação cultural em múltiplas instituições e equipamentos.

Este artigo toma como objeto o Serviço Educativo da Casa da Música e analisa os contornos sui generis de alguns projetos aí desenvolvidos. Procura compreender o modo como esses projetos incorporam uma dimensão "experimental" nas formas de relacionamento com públicos e no desenvolvimento de novos modos de promover a aproximação às práticas criativas no campo da música. Discutem-se ainda tendências de mudança mais amplas nas estratégias de mediação cultural em organizações artísticas, de que o caso estudado é ilustrativo.

Palavras-chave: equipamentos culturais; formação artística; inovação; instituições culturais; mediação cultural; política cultural; Serviço Educativo da Casa da Música.

\section{Introdução}

A esfera da cultura sofreu, nas últimas décadas, um conjunto de importantes transformações, ganhando um reconhecimento político e uma centralidade económica e social inédita. Estas transformações relacionam-se em parte com o modo como o Estado tem procurado reorientar as suas políticas nesta matéria, surgindo nos últimos anos novas estratégias de intervenção e novas temáticas e agendas, no âmbito das quais se espera que as artes e a cultura venham a dar respostas e contributos significativos para o desenvolvimento

\footnotetext{
* Por vontade do autor, este artigo segue a nova ortografia.
} 
socioeconómico das cidades e dos territórios. Por outro lado, generaliza-se a ideia de que o acesso à cultura deve ser encarado como um elemento de cidadania contemporânea, constituindo um importante instrumento de reforço da integração e coesão social.

Neste contexto, o papel da mediação na formação da prática cultural e na relação que os indivíduos estabelecem com as artes e a cultura adquire um interesse renovado, não só por parte das ciências sociais (e da sociologia em particular), ${ }^{1}$ como também por parte dos políticos, instituições e agentes que lidam com esse setor. Em Portugal, este interesse tem-se traduzido no desenvolvimento de serviços educativos em diversos tipos de instituiçõos culturais. Esta tendência é particularmente notória nos últimos anos, fruto do investimento público na criação/recuperação de infraestruturas culturais, de âmbito local e nacional, muitas vezes acompanhado pela constatação das reduzidas ou insuficientes audiências para a oferta das atividades culturais propostas por estes novos equipamentos (Santos, 1998; 2005). A criação de serviços educativos em Portugal começa por adquirir uma expressão relevante durante a década de 1980, acompanhando o boom de novos museus um pouco por todo o país, estendendo-se progressivamente a outros domínios culturais e artísticos ao longo das décadas seguintes. Atualmente, encontramos projetos e atividades educativas e/ou dirigidas a segmentos de público específicos em diferentes domínios: museus, bibliotecas, teatros e cineteatros, centros culturais e espaços patrimoniais (Gomes e Lourenço, 2009). Para além destes diferentes equipamentos e instituições culturais, os próprios apoios públicos às estruturas artísticas profissionalizadas enquadram, cada vez mais, de forma direta ou indireta, a captação e a "formação de públicos", questões hoje claramente assumidas como prioridades políticas.

A aposta na criação de serviços educativos vem-se assim revelando crescentemente diversa e necessita por isso de ser estudada, nos seus objetivos, procedimentos e efeitos. Tratando-se de um campo de ação cultural em transformação, mas ainda pouco estudado no nosso país, importa investigar como estão os serviços educativos a reinventar o modo de relacionamento dos públicos com as instituições culturais e, de forma mais ampla, com a prática artística e criativa.

É precisamente nesse campo de pesquisa que se posiciona o presente artigo, centrando-se na Casa da Música e nas estratégias de mediação cultural que esta instituição cultural dedicada à música tem desenvolvido através do

\footnotetext{
${ }^{1}$ Para uma revisão e discussão alargada da importância que vem sendo concedida ao conceito de mediação na literatura sociológica, cf. Ferreira (2002, 2006 e 2009).
} 
seu Serviço Educativo. ${ }^{2}$ Pela sua natureza, o caso em análise permite-nos investigar formas de mediação inovadoras e de caráter experimental, cujos efeitos se podem verificar não só ao nível da mobilização de públicos, mas também do modo como estes se relacionam com a música e a prática criativa (ou seja, formação para as artes, no sentido mais substantivo). A análise deste Serviço Educativo permite evidenciar o modo como algumas instituições, nas suas estratégias de intermediação cultural, tentam adequar a sua oferta de serviços às profundas mudanças que afetam hoje o seu campo específico de intervenção e, ao mesmo tempo, compreender alguns dos fatores que favorecem a adoção de estratégias de mediação inovadoras ou experimentais no contexto de uma grande organização cultural.

\section{Mediação cultural e serviços educativos: dos museus às instituições musicais}

Desde os anos 1970 que a questão da mediação cultural assume uma clara relevância política e programática na Europa, evidenciada por discursos e práticas que sublinham a importância do desenvolvimento de programas de formação, qualificação e atração de públicos para as artes e a cultura. Entende-se, nesse contexto, a mediação cultural como um imperativo social (Lamizet, 1999), numa visão que sublinha a importância da cultura como sustentáculo civilizacional, associada quer à manutenção de uma certa memória histórica e social, quer à construção de determinados cânones de sociabilidade no espaço público - aqui entendido num sentido ideal-típico, enquanto contexto particularmente favorável ao desenvolvimento de práticas coletivas de sociabilidade e de cidadania ativa.

Apesar das crescentes críticas a que esta visão algo sacralizada da cultura tem sido sujeita, constata-se que ela ainda sustenta, do ponto de vista ideológico, o desenvolvimento de muitas políticas culturais contemporâneas. Este é um entendimento profundamente associado aos princípios republicanos

\footnotetext{
${ }^{2}$ A análise aqui apresentada resulta da investigação realizada no âmbito da dissertação de Mestrado em Cidades e Culturas Urbanas (Faculdade de Economia da Universidade de Coimbra), entre 2009 e 2010. Privilegiou-se uma abordagem intensiva do Serviço Educativo da Casa da Música, adotando uma metodologia de cariz qualitativo. Foram entrevistados 23 atores inseridos em diferentes contextos: Direção da Fundação Casa da Música (gestão e programação artística); Serviço Educativo (Coordenação, Gestão de Projeto e Relações Públicas; Fator E; monitores da Digitópia); parceiros institucionais envolvidos em alguns dos projetos do Serviço Educativo. Foram também relevantes conversas informais mantidas com indivíduos ligados ao Serviço Educativo no decorrer da pesquisa. Efetuou-se ainda trabalho de campo, assistindo a diversos workshops, concertos, palestras e outros eventos promovidos pelo Serviço Educativo no interior e exterior da Casa da Música. Finalmente, analisou-se documentação de cariz institucional (produzidos pela Fundação Casa da Música e pelo seu Serviço Educativo), artigos científicos produzidos por alguns dos membros e parceiros institucionais do Serviço Educativo e artigos de imprensa escrita. Privilegiou-se nesta análise a atividade desenvolvida pelo Serviço Educativo entre 2006 e 2009.
} 
franceses da "democratização cultural", que defende a importância do acesso generalizado às artes e à cultura e que, cada vez mais, encontra nas práticas e consumos culturais um elemento de reforço da coesão social e da qualificação das competências individuais. Historicamente, esta é uma conceção das políticas culturais indissociável do processo de constituição do Estado-Providência na Europa do Norte e Centro, a partir do pós-II Guerra Mundial. No âmbito desse processo, o setor cultural veio a ser considerado, a par de outros, como um dos domínios de competência e atuação direta do Estado, fundamental para a criação de melhores condições de bem-estar e para o reforço da coesão social (Henriques, 2002: 66-67).

Apesar do contexto mais recente de retração do papel do Estado enquanto agente impulsionador da atividade artística e cultural, parece ser ainda no quadro desta conceção das políticas culturais, de matriz francófona e republicana, que podemos hoje compreender a importância que os serviços educativos assumem, como mecanismos de mediação cultural, na generalidade dos programas de divulgação e formação de públicos para a cultura propostos pelas organizações culturais. Mas convém igualmente assinalar que a crescente importância que as funções de intermediação cultural, aqui entendidas num sentido mais político e programático, assumem do ponto de vista da sustentabilidade das instituições culturais, é um aspeto cada vez mais decisivo no contexto atual de retração das políticas culturais. Saliente-se o impacto do envolvimento, nas equipas destas instituições, de técnicos oriundos das áreas do marketing e da gestão, tendo como objetivo delinear estratégias capazes de dotar esses espaços de maior visibilidade e, desse modo, "vender" melhor o serviço cultural, alargando as suas audiências e potenciais patrocinadores/mecenas (Hooper-Greenhill, 1994). Finalmente, esta disseminação de serviços educativos por diferentes tipos de instituições culturais - algumas das quais com pouca tradição a este nível, como os teatros ou a salas de ópera - não pode ser dissociada da maior relevância que, pelo menos no plano da retórica política, parece ser atribuída ao contributo das atividades artísticas e culturais para o reforço da coesão e da integração social.

Inicialmente pensados para o universo dos museus, as preocupações com a institucionalização dos serviços educativos e dos intermediários culturais que aí trabalham avançam de forma generalizada a partir de meados dos anos 1970, acompanhando transformações mais amplas ao nível das políticas culturais e educativas, que traduzem uma redefinição do entendimento do que é educar, aprender ou conhecer (Hooper-Greenhill, 1999; Hein, 1998; Martinho, 2007). Assiste-se, assim, a uma alteração progressiva da missão e objetivos de muitos serviços educativos dos museus, que ganham uma 
crescente autonomia face às funções tradicionais de preservação, estudo e valorização de coleções e exposições. As preocupações com a captação, envolvimento e acesso à cultura de diferentes comunidades e públicos ${ }^{3}$ têm acentuado múltiplas pressões para uma mudança nas abordagens expositivas e no modo como se trabalham nos museus as questões educativas (Black, 2005; Sandell, 1998 e 2003), propiciando uma atitude de maior experimentalismo e a busca de estratégias inovadoras. Por vezes, estas mudanças geram conflitos no seio dessas instituições, decorrentes da necessidade de promover uma conciliação entre as tradicionais responsabilidades e competências dos profissionais e a nova visão destes equipamentos como agentes ativos na promoção da inclusão social (Sandell, 1998 e 2003).

Face a este contexto, em que as instituições culturais são cada vez mais conduzidas a orientar a sua programação para responder a novos imperativos políticos, económicos e sociais, um crescente número de técnicos e investigadores questionam o que consideram ser uma certa subversão dos motivos que fundamentam a existência de alguns equipamentos, que tendem a "moldar" os seus objetivos de forma a justificarem os apoios públicos (Sandell, 1998: 416; Belfiore, 2002: 103).

É no campo museológico que o esforço de definição e tipificação de linhas de intervenção e também de institucionalização dos serviços educativos se encontra notoriamente mais avançado. Em outros domínios, o desenvolvimento de estruturas educativas em instituições culturais tem ocorrido igualmente, ainda que de uma forma heterogénea, contrastando em geral com a abordagem museológica, devido ao seu caráter menos estruturado do ponto de vista político e técnico-científico. É o caso das organizações culturais ligadas à música, onde o nível de estruturação e de tipificação da intervenção em termos educativos evidencia, em geral, um menor grau de institucionalização. No caso português, constata-se que, embora existam algumas iniciativas de desenvolvimento de projetos educativos em instituições ligadas à música, estas experiências têm geralmente um caráter pontual e disperso. Por outro lado, as tentativas de articulação entre as esferas da cultura e da educação artística (incluindo o ensino de música) - outra das vias centrais para a sensibilização/formação de públicos e estímulo ao desenvolvimento de atividades artísticas e criativas - evidenciam um caráter muito isolado e ocasional, apesar do amplo consenso político sobre esta matéria e, inclusivamente, dos três grupos de trabalho interministerial constituídos em

\footnotetext{
${ }^{3}$ Estas preocupações devem ser também compreendidas à luz de um contexto mais amplo em que se tende a exigir que os investimentos públicos em cultura se justifiquem pelos impactos, diretos e induzidos, que poderão gerar, designadamente em termos económicos e sociais (Belfiore, 2002; Matarasso, 1997).
} 
Portugal, desde 1996, para apresentarem propostas concretas de articulação neste âmbito (Gomes e Lourenço, 2009: 50). ${ }^{4}$

O campo da música tem sofrido um conjunto de profundas transformações, associadas, designadamente, aos intensos e acelerados processos de globalização e às possibilidades associadas à inovação tecnológica. Vem-se assistindo a uma expansão sem precedentes dos consumos e práticas musicais, intimamente ligada ao abundante uso de tecnologias na conceção, produção, distribuição, consumo e difusão da música (Théberge, 2001 e 2004; Pinch e Bijsterveld, 2004; Milner, 2009). As novas tecnologias - cada vez mais sofisticadas, miniaturizadas e económicas - constituem hoje elementos catalisadores desta mudança, contribuindo, através da transformação dos modos de produção, difusão e consumo, para a redefinição técnica e estética da música. Como refere Théberge (2001), o desenvolvimento de bomestudios, associados à disseminação de softwares de criação e gravação digitais, através do uso computador, constitui um dos mais marcantes traços da indústria musical contemporânea e do que designa por processo de "democratização" do mercado áudio, através da proliferação de uma estética de produção e distribuição de tipo do-it-yourself.

Neste contexto de profundas transformações, a análise de um serviço educativo como o da Casa da Música revela-se especialmente pertinente, já que permite equacionar algumas das mais recentes modalidades de relacionamento dos indivíduos com a música, seja enquanto consumidores, seja enquanto produtores. Para além disso, e como veremos, as caraterísticas específicas desse Serviço proporcionam um terreno privilegiado para a sondagem de algumas das estratégias de mediação cultural emergentes - inovadoras ou experimentais - que algumas organizações culturais contemporâneas concebem e implementam em resposta às transformações mais amplas da esfera cultural.

\section{A Casa da Música e o seu Serviço Educativo}

A Casa da Música é um equipamento cultural dedicado exclusivamente à música, criado no contexto da Porto 2001 - Capital Europeia da Cultura. Apresentado como um dos principais projetos que a Porto 2001 legaria à cidade e ao país, foi inaugurada quatro anos mais tarde, em 15 de abril de 2005. Em janeiro de 2006 instituiu-se a Fundação Casa da Música, tendo como entidades fundadoras o Estado Português, o Município do Porto, a Grande Área Metropolitana do Porto e 38 entidades de direito privado.

\footnotetext{
${ }^{4}$ Cf. igualmente Santos (1996), Silva (2000), Xavier (2004) e Fernandes (2007).
} 
Desde o início concebida para ser "a casa de todas as músicas", podemos identificar nos discursos oficiais em torno da missão e filosofia programática da Casa da Música referências explícitas a uma vocação de abertura a uma pluralidade de públicos e géneros musicais, à experimentação e à inovação - aspetos que, como veremos, são também estruturadores dos discursos em torno da missão e objetivos do Serviço Educativo. A programação da instituição caracteriza-se efetivamente por um grande ecletismo, apresentando um amplo leque de atividades: concertos, recitais e performances, promoção de encontros e seminários científicos, e ainda uma forte aposta na educação musical.

As questões educativas encontram-se, desde muito cedo, presentes nas preocupações programáticas da Casa da Música, iniciando-se as atividades do Departamento Educativo antes da abertura do equipamento, ainda no contexto da Porto 2001. É bastante relevador que o primeiro espetáculo apresentado na Casa da Música tenha sido um projeto de intervenção comunitária: a ópera "Demolição - A história que ides ver", concebida de raiz, que resultou de um trabalho com a população do bairro de Aldoar. Como sublinha Helena Santos (2003: 76), pretendeu-se com esse projeto evidenciar "uma abertura fortemente simbólica, do ponto de vista da construção da imagem do equipamento, ao dar prioridade, não ao acolhimento profissionalizado de espetáculos musicais, mas ao trabalho do Departamento Educativo".

Com a criação da Fundação da Casa da Música, a Direção Artística e de Educação passa a integrar o Serviço Educativo. No período aqui analisado (2006-2009), o Serviço Educativo era constituído por um coordenador e cinco colaboradores fixos, aos quais se associava uma equipa permanente de criadores responsáveis pela conceção e implementação da generalidade das atividades (designados por Fator E) e um conjunto diversificado de outros profissionais que, quando necessário, participavam em projetos específicos. Esta estrutura de recursos humanos, em comparação com outros setores da Casa da Música, era relativamente extensa, sendo apenas suplantada pelos departamentos de Programação Artística e de Produção.

Tendo como base a ideia de que "Educação não é sinónimo de escola e Música é muito mais do que uma atividade dos músicos que os outros estão destinados a contemplar" (S/A, 2009: 23), o Serviço Educativo da Casa da Música desenvolve uma programação regular composta por um conjunto muito diversificado de projetos e atividades. ${ }^{5}$ Nessas atividades, procura-se

\footnotetext{
5 A programação do Serviço Educativo da Casa da Música é composta por três tipos de atividades: as regulares, que decorrem ao longo de cada ano letivo; os projetos, com caráter pontual e de continuidade, direcionados para públicos-alvo específicos; e, por fim, espaços em permanência (Hot Spots), onde é possível explorar novas linguagens de criação musical e artística através do uso da tecnologia. O Serviço Educativo promoveu, entre 2006 e 2008, um total de 2456 atividades educativas, nas quais estiveram presentes 101816 pessoas (S/A, 2008a: 3).
} 
dar expressão a uma filosofia programática retoricamente sustentada em ideias de experimentalismo, ecletismo e inovação em relação às práticas convencionais e mais regulares de educação musical ou de formação para o convívio com a música. Atribui-se a esse projeto uma missão mais ambiciosa do que aquela que caracteriza a maioria dos serviços educativos: para além de promover a mobilização de públicos para a atividade da instituição e a sua formação para a relação com a música, pretende-se intervir de forma inovadora no próprio campo da formação e da criação musical.

Um dos eixos de intervenção do Serviço Educativo desenvolve-se ao nível das atividades regulares (workshops, concertos, ações de formação e conferências) que promove durante cada ano letivo. Ao longo do período aqui analisado, o Serviço Educativo apostou claramente no reforço da quantidade, qualidade e diversidade de workshops, estando esta oferta organizada em função de segmentos de público-alvo específicos. Durante a semana, a oferta de workshops dirige-se essencialmente a escolas do ensino básico e secundário, assim como a algumas comunidades específicas (por exemplo, centros de apoio à terceira idade, $\mathrm{ATLs}^{6}$ e IPSSs ${ }^{7}$ ). Desenhado para os diferentes níveis etários, os conteúdos dos workshops são diversificados, abordando aspetos rítmicos, de composição, exploração das relações entre a música e a matemática, a música e o movimento/corpo, entre outras questões.

Como revelam as entrevistas realizadas no âmbito da pesquisa que suporta este artigo, na ótica dos seus responsáveis - os membros do Fator E, equipa que assume a conceção e dinamização destas atividades o workshop constitui um formato de intervenção cultural e artística que se afigura particularmente flexível e adaptável aos diferentes tipos de segmentos de públicos, permitindo aos monitores introduzir alterações e mudanças de estratégia de abordagem, de acordo com os interesses e conhecimentos específicos de cada grupo. Por outro lado, os entrevistados reforçam as vantagens destas serem abordagens extremamente lúdicas e essencialmente práticas (enfatizando a importância de experimentar fazer música), sendo frequentemente apoiadas e/ou sustentadas por conteúdos tecnológicos.

A abundante utilização de tecnologia permite ainda ao Serviço Educativo encontrar novos espaços de intervenção, demarcando-se de abordagens com um pendor mais teórico e tradicionalista que, no essencial, constituem o cerne dos currículos escolares de ensino público da música (no qual a utilização do computador como instrumento musical, por exemplo, ainda

\footnotetext{
${ }_{6}$ Atelier de Tempos Livres.

${ }^{7}$ Instituição Particular de Solidariedade Social.
} 
se encontra praticamente ausente). Para além do uso da tecnologia, muitos entrevistados enfatizam a importância de as propostas abordarem géneros musicais distintos, numa opção deliberada por um forte ecletismo estético e técnico. Esta opção surge frequentemente associada a um posicionamento muito crítico relativamente ao ensino da música em Portugal, que acusam de excesso de conservadorismo e desatualização pedagógica. Voltaremos a esta questão mais adiante, mas é importante notar, desde já, que a equipa do Serviço Educativo é maioritariamente constituída por compositores e/ou músicos profissionais, muitos também professores e investigadores, o que significa que são detentores de uma autoridade específica, enquanto "especialistas" desta área de conhecimento, para desenvolverem este tipo de avaliação crítica das práticas de ensino da música em Portugal.

Embora as escolas constituam um dos principais públicos-alvo do Serviço Educativo da Casa da Música, foi possível concluir que, para a maioria (senão mesmo a totalidade) dos membros do Fator E, parece não existir uma preocupação com a articulação entre os conteúdos dos workshops e os programas escolares. Existe, por outro lado, a preocupação do Serviço Educativo não se sobrepor - ou fazer concorrência - às escolas de música. Este é, portanto, um trabalho em grande medida assumido como paralelo, que acaba por reforçar as esferas de autonomia em que as instituições se movimentam.

O leque da oferta de workshops do Serviço Educativo não se restringe ao público escolar. Constata-se uma forte concentração no fim de semana (por excelência, um período não letivo) de diversos workshops dirigidos a outro tipo de públicos. De entre outros segmentos, destaca-se a oferta dirigida seja às famílias, seja a músicos, profissionais ou amadores.

O alargamento da oferta regular de formação constitui uma das prioridades do Serviço Educativo da Casa da Música, que tem apostado numa articulação/complementaridade da oferta formativa com a realização de diversos projetos que, com diferentes durações, apresentam abordagens menos convencionais ou mais experimentais (nas técnicas utilizadas e nos contextos locais em que se inserem), assumindo geralmente um conjunto de preocupações específicas com os públicos-alvo a quem se dirigem.

\section{Mediação como intervenção: instrumento ao serviço da inclusão e coesão social?}

Anualmente, o Serviço Educativo promove outros projetos pontuais (com duração variável), direcionados para segmentos mais específicos, comparativamente com as audiências a que se destinam as atividades regulares que já referimos. Trata-se essencialmente de projetos de intervenção comunitária, 
um dos domínios em que, como vimos, a ação cultural tende a assumir muita relevância em termos políticos, económicos e sociais.

Eleonora Belfiore (2002) refere que se vem assistindo a uma certa "instrumentalização" das políticas culturais, que justificam grande parte do investimento público com os impactos sociais (supostamente) positivos deste tipo de projetos. Esta é uma tendência recente das políticas culturais, que não deve dissociar-se de um certo fracasso e frustração perante os resultados escassos de algumas experiências que, durante os anos 1980 e 1990, insistiram numa estreita associação das políticas culturais às retóricas da regeneração urbana, procurando evidenciar as potencialidades da cultura enquanto alavanca do desenvolvimento de cidades e dos territórios. Contudo, os resultados esperados acabaram frequentemente por ficar aquém das expectativas iniciais. Assim, tem-se verificado, nos últimos anos, um certo redireccionamento desta argumentação, alargando-se o conceito de regeneração urbana para passar a incorporar novas preocupações relacionadas com a qualidade de vida das populações e a coesão social das cidades e dos territórios. A propósito do caso inglês, Belfiore demonstra como o papel crescentemente relevante das autoridades locais na promoção e desenvolvimento de políticas de apoio à cultura está intimamente associado à importância que é hoje atribuída pelas políticas culturais ao impacto social das atividades artísticas.

Embora o debate sobre o impacto social dos projetos e organizações culturais não se encontre tão aprofundado em Portugal, a verdade é que também aqui as retóricas da inclusão social parecem invadir progressivamente as políticas culturais. Esta mudança origina necessariamente alterações nas missões e estratégias de intervenção levadas a cabo por diversas instituições culturais - ou nas suas necessidades de legitimação pública. Neste quadro, também aos profissionais da cultura, em especial aqueles que atuam como intermediários culturais, são exigidas novas competências e a capacidade de reinventarem o seu papel e métodos de trabalho e atuação e, assim, encontrarem um novo posicionamento. Encontramos na Casa da Música, tanto nos seus projetos de intervenção, quanto nas retóricas que os justificam, uma estratégia que procura ir ao encontro destes desafios.

A programação da Casa da Música está ainda bastante centrada na realização de concertos. Não surpreende, por isso, que o Administrador-Delegado da Fundação Casa da Música considere, em entrevista, que "o Serviço Educativo é um veículo excecional para estabelecer parcerias na sociedade em que nós nos inserimos”. Realça a importância estratégica, para a organização cultural que administra e dirige, da crescente visibilidade que, a diversos níveis, muitos dos projetos mais orientados para 
a intervenção comunitária têm obtido junto dos media - em virtude dos públicos envolvidos e das soluções técnicas e artísticas que se pretendem originais e inovadoras:

O que é muito positivo, por exemplo, do ponto de vista dos nossos patrocinadores e mecenas, que veem o nosso trabalho também nesta área a ser publicamente reconhecido e com uma grande originalidade, criatividade, etc. [...] Mas, melhor ainda, o facto de termos uma atitude experimentalista, de tentarmos coisas novas, etc., isso tem atraído também muito a atenção de pessoas fora de Portugal, que estudam estas matérias e temos tido vários dos nossos projetos [...] que passaram a ser projetos de referência no âmbito das redes organizadas na Europa que se ocupam deste tipo de setor. (Excerto de entrevista ao Administrador-Delegado da Fundação Casa da Música)

Um dos projetos de média duração do Serviço Educativo é o Curso de Formação de Animadores Musicais, dirigido a professores de música, músicos profissionais e estudantes de música do ensino superior. Ao longo de um ano letivo, pretende-se fornecer ferramentas de trabalho para a animação e liderança, através da música, de diversos tipos de comunidades. No final de cada ano, acontece a apresentação pública de um espetáculo, o "Sonópolis", integrando um conjunto de ensembles provenientes de contextos (sociais e musicais) muito diversificados, que se reúnem para apresentar parte do trabalho desenvolvido com os animadores musicais formados.

Outra das atividades regulares do Serviço Educativo é o "A Casa vai a casa", dirigido a instituições que, por diversos motivos, não podem deslocar-se à Casa da Música. Este projeto tem desenvolvido trabalho pontual, num número variável de sessões, em espaços de instituições como IPSSs, centros de reabilitação, hospitais ou estabelecimentos prisionais - um dos exemplos mais citados, tendo sido inclusivamente objeto de apresentações em conferências e encontros científicos, é o projeto "Bebé Bábá" que, em 2008, envolveu bebés e mães de reclusas no Estabelecimento Prisional Feminino de Santa Cruz do Bispo.

Constata-se, assim, que em muitos dos projetos do Serviço Educativo existem claras preocupações com a capacidade de intervenção da Casa da Música ao nível do que habitualmente se designa por "democratização cultural" e "promoção da inclusão social" através das artes - neste caso, o acesso a práticas de criação e fruição musical -, tendo como públicos-alvo, nas palavras dos responsáveis da instituição, "cidadãos que por norma têm um acesso limitado a experiências artísticas enriquecedoras” (S/A, 2008b: 30). Para muitos membros do Serviço Educativo, é justamente nos projetos 
de intervenção comunitária que se evidenciam alguns dos exemplos mais claros do "pioneirismo" - numa alusão que remete claramente para as primeiras experiências de intervenção comunitária desenvolvidas pela Casa da Música ainda no contexto da Porto 2001 - e da "inovação" procurados pela instituição.

A atenção dedicada às pessoas com deficiência constitui outra das áreas em que o Serviço Educativo da Casa da Música mais se tem evidenciado. Desde 2007, realiza-se em abril o Festival "Ao Alcance de Todos - Música, Tecnologia e Necessidades Especiais”, envolvendo um conjunto bastante alargado de associações e instituições, para além de investigadores e músicos que têm trabalhado abordagens a diferentes tipos de deficiências através da música.

Na edição de 2009 do "Ao Alcance de Todos", por exemplo, o Serviço Educativo promoveu o projeto "Instruments For Everyone", desenvolvido por Rolf Gehlaar, Rui Penha e Luís Girão. O projeto envolveu quatro instituições, com utentes portadores de deficiências distintas, para os quais foram criadas, durante meses, soluções específicas - e, até ao momento, inéditas - que lhes permitissem, através destes instrumentos, produzir e criar música. Durante o Festival realizaram-se diversas apresentações relacionadas com o projeto, orientadas para dois tipos de públicos distintos: workshops de demonstração dos instrumentos, tendo como objetivo permitir um primeiro contacto de indivíduos com diferentes necessidades especiais com a produção de som; e sessões técnicas para músicos e terapeutas, sobre os modos de produção e aplicação desses instrumentos. Posteriormente, foram disponibilizados gratuitamente on-line os manuais contendo indicações para a construção dos instrumentos. Foram ainda entregues às instituições envolvidas no projeto os protótipos desenvolvidos pelo Serviço Educativo.

O "Instruments For Everyone" é apenas um dos exemplos de projetos do Serviço Educativo que nos permitem reequacionar o tipo de estratégias de intermediação cultural postas em prática por organizações culturais deste tipo, no âmbito das quais se desenham novas modalidades de aproximação entre mediação, criação e investigação e desenvolvimento. Sublinhe-se o papel da tecnologia enquanto elemento-chave no processo de intermediação cultural, que possibilita a determinados segmentos da população o acesso a momentos de criação, produção e fruição musical, aspeto realçado por diversos entrevistados. É ainda importante assinalar que a concretização de um evento com as características inovadoras do "Ao Alcance de Todos" implica necessariamente um forte investimento da Casa da Música. Esta é uma das áreas em que a ação cultural (e também social) do Serviço Educativo tende a assumir-se como uma verdadeira "imagem de marca" da instituição, 
reiterada e consolidada projeto após projeto, o que parece não só reforçar a ideia da importância do "alcance social" das suas atividades, como também evidencia a relevância estratégica do forte investimento em investigação e desenvolvimento de conteúdos pedagógicos inovadores e originais.

\section{O lugar da tecnologia, da inovação e da experimentação na mediação cultural}

O "Instruments for everyone" e outros projetos desenvolvidos pelo Serviço Educativo suscitam a questão relativa à crescente importância que, a diferentes níveis, a tecnologia assume na produção e consumo de música na contemporaneidade. ${ }^{8}$ Autores como Antoine Hennion $(1997,2003)$ e Sophie Maisonneuve (2001a e 2001b) têm alertado para a necessidade de incorporar na análise das relações sociais em torno da música uma ampla gama de mediadores "técnicos" que, para além dos "humanos", influem decisivamente nos processos sociais através dos quais se configuram diferentes predisposições e gostos para práticas e consumos culturais. Hennion $(1997,2003)$ propõe a esse respeito uma "sociologia relacional", capaz de entender o trabalho artístico como uma mediação, cujo resultado é produto da incorporação de uma multiplicidade de agentes - humanos e "não-humanos" - que, conjuntamente, se inter-relacionam.

À luz desta orientação analítica, alguns dos projetos do Serviço Educativo que mais utilizam elementos tecnológicos permitem-nos alargar a discussão em torno das múltiplas formas através das quais os indivíduos se relacionam com a música. Neste contexto, a tecnologia assume-se como uma ferramenta essencial na busca de novas soluções, capazes de ir de encontro às diferentes necessidades e interesses dos diversos públicos. Simultaneamente, a aposta na criação e disponibilização de soluções próprias contribui para distanciar e diferenciar este Serviço Educativo da generalidade das abordagens existentes neste campo.

Esta estratégia de mediação cultural está fortemente assente na ideia da livre exploração da música, essencialmente através do recurso às novas tecnologias. Centremo-nos no caso da "Digitópia - Plataforma para o desenvolvimento de comunidades de criação musical em computador", um dos projetos mais paradigmáticos que, neste plano, podemos encontrar no Serviço Educativo da Casa da Música. A Digitópia reúne um conjunto de dimensões que, como veremos, se alinham com algumas das principais transformações atualmente em curso nos processos de mediação cultural e,

\footnotetext{
${ }_{8}^{8}$ Vejam-se, a este respeito, os trabalhos de Jones (2002), Throsby (2002), Abreu (2000), Pinch e Bijsterveld (2004), Théberge (1997, 2001 e 2004) e Taylor (2001).
} 
em particular, no modo como estas se manifestam nas práticas de criação e produção artística no campo da música.

Localizada no ball de entrada da Casa da Música, a Digitópia é um espaço de experimentação e criação musical, composto por diversas ferramentas: computadores, auscultadores, controladores midi de diferentes formatos, microfones, colunas, etc. A proposta é possibilitar o acesso ao espaço e à utilização dos recursos técnicos existentes sem necessidade de acompanhamento ou marcação prévia. Contudo, também se pode contar com o apoio/orientação de um monitor. O espaço é ainda utilizado para workshops e para sessões intensivas de formação, de curta duração, dirigidas a públicos mais especializados.

As primeiras experiências do Serviço Educativo no domínio da experimentação da atividade de criação musical através do uso do computador iniciaram-se em 2005, com a abertura da Casa da Música, designadamente, através dos workshops para escolas "CyberSom" e "HyperScore", um software desenvolvido por Tod Machover do MIT Media Lab. Com o projeto da Digitópia, passou a contemplar-se a conceção e desenvolvimento de softwares open-source de criação musical próprios (casos do "Políssonos", "Narrativas Sonoras" e "Digital Jam", desenvolvidos pelo compositor Rui Penha, membro do Fator E). Este é um dos aspetos mais inovadores da abordagem deste Serviço Educativo, uma vez que lhe permite distanciar-se de abordagens mais comuns, indiciando uma nova convivência entre as esferas da criação, da investigação aplicada e da intermediação e ação cultural. ${ }^{9}$ Para além disso, tem-se assistido, desde 2007, à participação regular da Digitópia em congressos científicos e outros fóruns internacionais de discussão especializada.

Se no contexto da Digitópia a mediação tecnológica se revela omnipresente e decisiva na relação que os utilizadores estabelecem com a música, a mediação humana intervém de forma igualmente relevante, suscitando processos complexos de partilha de aprendizagens e trabalho criativo entre os vários intervenientes (criadores de software, responsáveis pela conceção da plataforma, utilizadores e monitores). Nesse quadro, tornam-se muito indistintas as fronteiras entre intermediação, criação e formação/receção.

A ação dos monitores da Digitópia ganha, neste plano, um significado particularmente interessante. Ao longo da investigação realizada na Casa da Música foi-se tornando mais clara a relevância assumida, a diferentes

\footnotetext{
${ }^{9}$ Note-se que a génese da Digitópia surge de uma parceria entre a Casa da Música e três instituições de ensino superior e investigação científica do Porto: o Instituto de Engenharia de Sistemas e Computadores do Porto, a Escola Superior de Música e das Artes do Espetáculo e a Escola das Artes da Universidade Católica Portuguesa.
} 
níveis, pelos monitores na relação estabelecida entre o público, o espaço da Digitópia e os elementos tecnológicos nele contidos. O seu trabalho de base reside na familiarização dos utilizadores com a criação e a manipulação musical por computador, atuando portanto como mediadores da relação entre os públicos e esse outro mediador "não-humano", a tecnologia, segundo os interesses específicos e os conhecimentos prévios de cada um. No entanto, tanto a observação direta, como as entrevistas permitiram perceber o modo como alguns dos monitores incorporaram, no decurso da sua experiência de trabalho, novas atribuições e desempenhos, que estendem o seu papel de mediadores.

Com efeito, o trabalho de acompanhamento técnico dos utilizadores acaba por se esgotar rapidamente ao fim de poucas sessões, na justa medida em que estes adquirem autonomia no uso da tecnologia, podendo a partir daí manipulá-la noutros contextos como, por exemplo, nos seus estúdios caseiros. Os monitores, porém, prolongam a sua ação para outros domínios muito relevantes da relação dos públicos da Digitópia com a música e a criação. Funcionam como agentes capazes de formular e partilhar juízos e orientações estéticas - por exemplo, estabelecendo diálogos em torno de referências musicais, aconselhando opções de mistura de som, de utilização de efeitos sonoros ou de escolha dos softwares mais indicados para as práticas de manipulação musical que os utilizadores pretendem realizar.

Em entrevista, os monitores valorizam muito estes aspetos complementares da sua função, entendendo-os quer como elementos centrais da autorrepresentação do seu papel como mediadores, quer como fatores decisivos para a fidelização dos públicos da Digitópia. Para a reconfiguração que, por essa via, produzem na sua função, no quadro da qual se tornam mais indistintas as fronteiras entre o trabalho técnico de mediação e o trabalho criativo (ou a partilha de orientações criativas), concorre decisivamente o seu perfil. Sendo maioritariamente compositores e/ou músicos e podendo, portanto, facilmente mobilizar repertórios relevantes para o trabalho criativo, projetam a sua experiência e as suas predisposições artísticas na relação que estabelecem com os públicos, ampliando a função de cariz mais eminentemente técnica e assistencial originalmente prescrita para os monitores.

\section{O Fator E e a conceção de produtos inovadores}

O perfil e o papel dos monitores da Digitópia introduz uma outra questão de grande importância estratégica para o modo como as instituições culturais desenvolvem trabalho de mediação, nomeadamente no contexto dos seus serviços educativos: a dimensão, o perfil e as qualificações das equipas de trabalho e a sua maior ou menor adequação à missão e objetivos da 
instituição. A constituição de uma equipa criativa permanente do Serviço Educativo, responsável pela conceção, implementação e dinamização das atividades educativas - o Fator $\mathrm{E}$ - reflete precisamente esta preocupação. Mais do que isso, exprime a intenção estratégica da Casa da Música de apresentar, ao nível da sua oferta educativa, um conjunto de soluções específicas - "inovadoras", segundo os discursos dos entrevistados -, capazes de diferenciarem este Serviço Educativo dos departamentos educativos de outras instituições culturais semelhantes. A constituição da equipa foi guiada pela intenção de conquistar para a instituição, e sobretudo para o seu Serviço Educativo, uma legitimidade assente na afirmação de um caráter original e diferenciador no espaço cultural, mas também baseada na forte presença de competências artísticas, técnicas e criativas vinculadas ao campo musical.

Os diferentes perfis dos dez elementos que, no período analisado, compunham o Fator $\mathrm{E}$ atestam, na sua diversidade, isso mesmo: uns estão próximos das áreas da pedagogia da música, outros da composição, outras das novas tecnologias, do canto, da percussão, outros ainda do design e multimédia. Esta heterogeneidade reflete um esforço deliberado de, sem abdicar de uma forte componente associada à área de especialidade (a música), diversificar o leque de abordagens possíveis, apostando no cruzamento de perspetivas distintas e, simultaneamente, procurando favorecer a criação e produção artística própria em diversos planos: quer em termos de conceção de workshops e atividades educativas; quer ao nível da criação e desenvolvimento de soluções técnicas e tecnológicas originais; quer ainda entendendo o Fator E como ensemble artístico de pleno direito, capaz de criar e apresentar peças originais. Saliente-se, por exemplo, a instituição de encontros mensais - as "Residências" - com o propósito de propiciar novas abordagens, favorecer a experimentação e estimular a discussão e o debate interno sobre as várias propostas a apresentar.

A criação do Fator E deve ser ainda entendida à luz da ideia de que "as atividades educativas são uma área da programação", como defende o ex-coordenador do Serviço Educativo, Paulo Maria Rodrigues. Em entrevista, sublinha que as atividades educativas "têm uma identidade própria, têm públicos, têm filosofias próprias, têm estéticas próprias" e recusa a subordinação a outras áreas da programação artística, numa lógica de "formação ou angariação de públicos". Este entendimento, que conjuga a reivindicação de autonomia do Serviço Educativo no interior da instituição com a afirmação de que o trabalho de mediação é também trabalho criativo original, constitui um tópico central do discurso da esmagadora maioria dos entrevistados. Estes veem na autonomia do Serviço Educativo e na possibilidade de desenvolverem, enquanto Fator E, abordagens simultaneamente 
artísticas e educativas, uma condição que inequivocamente favorece o surgimento de "soluções inovadoras". Mas favorece também, diríamos, a afirmação da equipa e dos seus membros no interior do campo musical, sustentada nessa capacidade de inovação que reivindicam para o seu trabalho.

Xavier Castañer e Lorenzo Campos (2002) chamam justamente a atenção para a importância de, na análise das determinantes da inovação artística, se olhar para a estrutura organizativa e procurar compreender o "diferencial" existente entre as performances efetivas e as aspirações/ambições da organização cultural, tentando perceber de que modo estas motivam (ou constrangem) a inovação artística. Os autores defendem, nomeadamente, que os recursos humanos disponíveis, as suas motivações pessoais e o modo como se integram na estrutura organizativa constituem fatores decisivos para a emergência da inovação artística.

$\mathrm{Na}$ Casa da Música, foi possível perceber que não só o contexto multidisciplinar e de forte interação entre os diversos membros do Fator E favorece o surgimento de novas soluções, como os seus próprios percursos e interesses profissionais/artísticos influem positivamente na emergência das diferentes abordagens. Saliente-se que vários membros do Fator E desenvolvem investigação ou planeiam avançar para estudos pós-graduados em áreas científicas estreitamente relacionadas com o trabalho que realizam na Casa da Música. Em entrevista, houve ainda quem afirmasse que esta experiência profissional se refletiu diretamente nos seus processos de trabalho enquanto artista e professor (fora da Casa da Música), considerando que a prática de trabalho multidisciplinar e, como alguns afirmam, "de laboratório", tem constituído um forte estímulo criativo. Importa ainda não negligenciar que o anterior coordenador do Serviço Educativo é ele próprio músico e professor universitário, com um percurso profissional e artístico associado a projetos de intervenção comunitária, assentes não só na música, mas também em abordagens artísticas multidisciplinares.

Estes diferentes aspetos, relacionados com os perfis, as trajetórias, as motivações e a inserção organizacional dos profissionais, são fundamentais para a compreensão dos fatores que favorecem a emergência de novas abordagens e a dinâmica de inovação gerada no Serviço Educativo. Como defendem Castañer e Campos (2002: 43-44), a análise da inovação nas organizações culturais deve prestar uma atenção especial aos antecedentes de cada um dos agentes, em particular dos gestores e dirigentes (em termos de formação artística, académica e de experiência profissional), percebendo de que forma podem estes aspetos, de algum modo, determinar as orientações estratégicas quanto ao posicionamento da instituição e favorecer (ou não) a emergência de aspetos de inovação artística. Os elementos analisados 
indiciam um conjunto específico de condições que favorecem práticas de experimentação e de inovação artística e pedagógica, contribuindo decisivamente para diferenciar, na área educativa, as estratégias de mediação cultural da Casa da Música.

\section{Conclusão}

Ao longo do artigo procurámos analisar o Serviço Educativo da Casa da Música, partindo da forma como se encontram estruturados os seus objetivos e estratégias de intervenção e salientando os aspetos que se afiguram mais relevantes para compreender o lugar que o experimentalismo e a inovação, mas também a autonomia programática, desempenham quer na sua atuação, quer na retórica com base na qual esse Serviço constrói a sua própria identidade e se procura legitimar como ator cultural e educativo no campo musical.

Como vimos, os serviços educativos constituem hoje uma área estratégica para muitas organizações culturais, quer porque permitem concretizar uma visão programática das artes e da cultura como ferramentas para a coesão e integração social, quer porque através deles se constroem também as trajetórias e as reputações da instituição e dos seus membros. O caso do Serviço Educativo da Casa da Música e da programação que desenvolve revela-se, a este nível, especialmente interessante, ao evidenciar preocupações crescentes com a apresentação de propostas diversificadas, orientadas para audiências cada vez mais alargadas. A capacidade de estruturar e propor uma oferta heterogénea de serviços parece apontar para uma tendência de crescente autonomização deste tipo de estruturas educativas no seio das organizações culturais em que se inserem, como é manifestamente o caso estudado.

De facto, se tradicionalmente cabia aos serviços educativos intermediar o contacto do público com a programação artística da instituição, no caso do Serviço Educativo da Casa da Música a pesquisa constatou uma programação educativa com razoável grau de autonomia, dispondo de lógicas de produção relativamente independentes (em termos de recursos humanos, logísticos e financeiros, mas também em termos criativos) e com estratégias de posicionamento no mercado cultural orientadas para públicos-alvo específicos.

A centralidade e a autonomia deste Serviço Educativo parece evidenciar a crescente complexidade e hibridização das estratégias de intermediação cultural que, em grande medida, decorre da maior complexificação do setor cultural (Benhamou, 1996). A multiplicidade de formas de difusão que hoje coexistem, em particular no mundo da música, envolve um conjunto diferenciado de agentes que desenvolvem o trabalho de intermediação cultural 
em contextos institucionais e organizacionais distintos e com condições de trabalho muito diversificadas. A intermediação cultural tende assim a englobar "um universo de atividades com fronteiras muito porosas e fluidas", conforme afirma Claudino Ferreira (2006: 71), enunciando "um campo de análise construído em torno de um conjunto de atividades e de atores que se distribuem por diversos domínios culturais, contextos organizacionais e áreas profissionais".

À medida que ocorre um alargamento da missão, objetivos e estratégias das organizações culturais, novas competências parecem ser exigidas a estes intermediários culturais, no sentido de reinventarem o seu papel, métodos de trabalho e formas de atuação. O caráter híbrido do Serviço Educativo da Casa da Música e dos agentes que o constituem - o Fator E - demonstra justamente a sobreposição de competências e o grau de exigência que hoje se colocam aos intermediários culturais: eles devem ser (ou querem ser) simultaneamente performers, criadores, pedagogos e técnicos. Alguns projetos do Serviço Educativo, pela complexidade de competências artísticas, técnico-científicas e pedagógicas que mobilizam, refletem precisamente este aspeto, ao mesmo tempo que denunciam reivindicações de autoria, análogas às que são típicas dos criadores artísticos. De facto, muito do trabalho de intermediação cultural desenvolvido pelos membros do Fator E, o autodesignado "ensemble educativo da Casa da Música", situa-se na confluência entre o universo da pura criação artística e os objetivos mais marcadamente pedagógicos, ligados ao desenvolvimento de conteúdos de introdução ao universo musical. As lógicas de atuação predominantes transformam algumas atividades do Serviço Educativo em objetos híbridos, localizados algures entre o workshop, a performance, o espetáculo e, mesmo, a investigação aplicada, como decorre da presença ativa que o Serviço mantém em fóruns académicos de discussão e do trabalho realizado em parceria com universidades e centros de investigação.

Esta hibridez, associada à multiplicidade e flexibilidade das abordagens, constitui um dos princípios basilares da filosofia programática do Serviço Educativo e parece ser uma estratégia para lidar de forma adaptativa com o contexto de mudança com que se confrontam hoje as organizações culturais. Tomando em consideração as transformações estruturais que vêm afetando o mundo da música, área por referência à qual a instituição em análise se posiciona culturalmente, concedemos particular atenção a dois aspetos principais: a interação entre os atores humanos e a tecnologia na mediação cultural e o papel desempenhado pela procura da inovação no trabalho de mediação. Na estratégia programática do Serviço Educativo da Casa da Música, os dois aspetos aparecem claramente associados e 
constituem uma das "pedras de toque" da identidade com base na qual a equipa procura conquistar legitimidade e reconhecimento no campo cultural. O recurso à articulação entre a mediação humana e a tecnológica no desenho da estratégia de relação com os públicos (e, portanto, de mobilização destes para a prática musical) constitui efetivamente uma das principais estratégias de busca de uma postura experimental e inovadora por parte do Serviço Educativo. Contudo, a ênfase na experimentação e na inovação está também estreitamente associada às características do contexto organizacional específico e dos perfis e trajetos dos profissionais envolvidos: um e outros revelam-se particularmente propensos, como a pesquisa mostrou, a valorizar a afirmação individual e institucional por via de um posicionamento diferenciador e, portanto, distintivo, em relação à generalidade das propostas disponíveis em estruturas semelhantes. Do lado dos profissionais, procurámos mostrar que os seus perfis e trajetórias os tornam particularmente propensos a uma atitude experimental e centrada na busca da inovação, que está em larga medida associada à forma como concebem o trabalho de mediação simultaneamente como trabalho de criação. Do lado da instituição, por seu turno, a autonomia e a filosofia experimental e inovadora do Serviço Educativo vai ao encontro da missão que a Casa da Música reclama para si, de tal modo que desde a origem apostou no Serviço Educativo como um elemento estratégico dessa missão, dotando-o de um orçamento próprio, equivalente ao de outros departamentos. Esta situação de relativo conforto económico permite que os seus profissionais raramente se confrontem com constrangimentos fortes ao desenvolvimento das suas ideias. Pelo contrário, como alguns dos entrevistados referiram, a possibilidade de disporem de recursos logísticos e financeiros constitui um estímulo à sua criatividade, incentivando-os a serem mais "arrojados" e a "experimentarem" novos tipos de abordagens.

Associados, estes diversos fatores fazem da Casa da Música e do seu Serviço Educativo um contexto especialmente desafiante para a sondagem dos modos através dos quais o trabalho de intermediação cultural se vem reinventando, sob a pressão de um conjunto de dinâmicas mais amplas que pautam a redefinição da cultura e do seu papel nas sociedades contemporâneas. Na sua singularidade, que, como procurámos mostrar, lhe confere uma especial saliência no atual contexto nacional, o caso do Serviço Educativo da Casa da Música ilustra o quanto essa reinvenção passa hoje pelo diálogo hibridizante entre esferas que longamente a abordagem sociológica autonomizou analítica e conceptualmente: entre a mediação e a criação, entre o institucional e o individual, entre o humano e o tecnológico, entre o artístico e o não-artístico. 


\section{Referências bibliográficas}

Abreu, Paula (2000), "Práticas e consumos de música(s): ilustrações sobre alguns novos contextos da prática cultural”, Revista Crítica de Ciências Sociais, 56, 123-147.

Belfiore, Eleonora (2002), "Art as a Means of Alleviating Social Exclusion: Does it really work? A Critique of Instrumental Cultural Policies and Social Impact in the UK", International Journal of Cultural Policy, 8(1), 91-106.

Black, Graham (2005), The Engaging Museum. Developing Museums for Visitor Envolvement. London \& New York: Routledge.

Benhamou, Françoise (1996), L'économie de la culture. Paris: La Découverte.

Castañer, Xavier; Campos, Lorenzo (2002), "The Determinants of Artistic Innovation: Bringing in the role of oirganizations", Journal of Cultural Economics, 26, 29-52.

Fernandes, Domingos (coord.) (2007), "Estudo de Avaliação do Ensino Artístico". Relatório Final.

Ferreira, Claudino (2002), "Intermediação cultural e grandes eventos. Notas para um programa de investigação sobre a difusão das culturas urbanas", Oficina do CES, 167.

Ferreira, Claudino (2006), “A Expo'98 e os Imaginários do Portugal Contemporâneo: Cultura, Celebração e Políticas de Representação”. Tese de Doutoramento em Sociologia. Coimbra: Faculdade de Economia da Universidade de Coimbra.

Ferreira, Claudino (2009), "Intermediários culturais e cidade", in Carlos Fortuna e Rogério Proença Leite (org.), Plural de cidade: novos léxicos urbanos. Coimbra: Almedina, 319-336.

Gomes, Rui Telmo; Lourenço, Vanda (2009), Democratização Cultural e Formação de Públicos: Inquérito aos "Serviços Educativos" em Portugal. Lisboa: Observatório das Atividades Culturais.

Hein, George (1998), Learning in the Museum. Oxon: Routledge.

Hooper-Greenhill, Eilean (1994), Museums and their Visitors. London: Routledge

Hooper-Greenhill, Eilean (coord.) (1999), The Educational Role of the Museum. London \& New York: Routledge [2. ${ }^{a}$ ed.].

Hennion, Antoine (1997), "Baroque and Rock: Music, mediators and musical taste", Poetics, 24, 415-435.

Hennion, Antoine (2003), "Music and Mediation: Toward a new sociology of music", in Martin Clayton; Trevor Herbert; Richard Middleton (orgs.), The Cultural Study of Music: A critical introduction. New York/London: Routledge.

Henriques, Eduardo Brito (2002), "Novos desafios e orientações das políticas culturais: tendências nas democracias desenvolvidas e especificidades no caso português", Finisterra, XXXVII, 73, 61-80.

Jones, Steve (2002), "Music that Moves: Popular music, distribution and network technologies", Cultural Studies, 16(2), 213-232.

Lamizet, Bernard (1999), La médiation culturelle. Paris: L'Harmattan. 
Maisonneuve, Sophie (2001a), "Between History and Commodity: The production of a musical patrimony through the record in the 1920-1930s", Poetics, 29, 89-108.

Maisonneuve, Sophie (2001b), "De la 'machine parlante' à l'auditeur. Le disque et la naissance d'une nouvelle culture musicale dans les années 1920-1930”, Terrain, $37,11-28$.

Martinho, Teresa Duarte (2007), Apresentar a arte. Estudo sobre monitores de visitas a exposições. Lisboa: Observatório das Atividades Culturais.

Matarasso, Franco (1997), Use or Ornament? The Social Impact of Participation in the Arts. Stroud: Comedia.

Milner, Greg (2009), Perfecting Sound Forever. The Story of Recorded Music. London: Granta Books.

Pinch, Trevor; Bijsterveld, Karin (2004), "Sound Studies: New technologies and music”, Social Studies of Science, 34/5, 635-648.

Sandell, Richard (1998), "Museums as Agents of Social Inclusion”, Museum Management and Curatorship, 17(4), 401-418.

Sandell, Richard (2003), "Social Inclusion, the Museum and the Dynamics of Sectoral Change", Museum and Society, 1(1), 45-62.

Santos, Helena (2003), "A propósito dos públicos culturais: uma reflexão ilustrada para um caso português”, Revista Crítica de Ciências Sociais, 67, 75-97.

Santos, Maria Emília Brederode (coord.) (1996), "Grupo Interministerial para o Ensino Artístico". Relatório/Síntese.

Santos, Maria de Lourdes Lima dos (1998), "Estado, mercado e sociedade civil", in Maria de Lourdes Lima dos Santos (org.), As políticas culturais em Portugal. Lisboa: Observatório das Atividades Culturais, 265-283.

Santos, Maria de Lourdes Lima dos (coord.) (2005), "Contribuições para a formulação de políticas públicas no horizonte 2013 relativas ao tema Cultura, Identidade e Património”. Relatório final. Lisboa: Observatório das Atividades Culturais.

Silva, Augusto Santos (coord.) (2000), “A educação artística e a promoção das artes, na perspetiva das políticas públicas”, Relatório do grupo de contacto entre os Ministérios da Educação e da Cultura. Lisboa: Editorial do Ministério da Educação.

S/A (2008a), “Casa da Música Serviço Educativo Out. 2008 - Jun. 2009”. Porto: Casa da Música.

S/A (2008b), "Relatório e Contas 2008 Fundação Casa da Música". Porto: Casa da Música.

S/A (2009), "Casa da Música/Galp Energia - Mecenas do Serviço Educativo". Porto: Casa da Música.

Taylor, Timothy (2001), Strange Sounds. Music, Technology \& Culture. New York/ London: Routledge.

Théberge, Paul (1997), Any Sound You Can Imagine. Making Music/Consuming Technology. Hanover/London: Wesleyan University Press. 
Théberge, Paul (2001), “Plugged in': technology and popular music”, in Simon Frith; Will Straw; John Street (orgs.), The Cambrigde Companion to Pop and Rock. Cambrigde: Cambrigde University Press, 3-25.

Théberge, Paul (2004), "The Network Studio: Historical and technological paths to a new ideal in music making, Social Studies of Science, 34/5, 759-781.

Throsby, David (2002), "The Music Industry in the New Millenium: Global and local perspectives", paper prepared for The Global Alliance for Cultural Diversity. Paris: UNESCO - Division of Arts and Cultural Enterprise.

Xavier, Jorge Barreto (coord.) (2004), Relatório do Grupo de Trabalho - Ministério da Educação e Ministério da Cultura - Despacho Conjunto n 1062/2003 - DR-II série de 27 de novembro.

\section{Outras fontes de informação consultadas}

Website da Casa da Música: www.casadamusica.com 